\title{
Relationship between UGTIAI*6/*28 gene polymorphisms and the efficacy and toxicity of irinotecan-based chemotherapy
}

This article was published in the following Dove Press journal:

OncoTargets and Therapy

19 June 2017

Number of times this article has been viewed

Yu Bai

Hai-wei Wu

$\mathrm{Xu} \mathrm{Ma}$

Ying Liu

Yan-hua Zhang

Key Laboratory of Carcinogenesis and Translational Research (Ministry of Education), Department of Pharmacy, Peking University Cancer Hospital and Institute, Beijing, People's Republic of China
Correspondence: Yan-hua Zhang Key Laboratory of Carcinogenesis and Translational Research (Ministry of Education), Department of Pharmacy, Peking University Cancer Hospital and Institute, No 52, Fu Cheng Road, Hai Dian District, Beijing I00|42, People's Republic of China

$\mathrm{Tel}+8601088196206$

Email zyh88I2@I63.com
Purpose: A retrospective study was performed to analyze the relationship between uridine diphosphate glucuronosyltransferase $1 \mathrm{~A} 1($ UGT1A1) *6/*28 gene polymorphisms and adverse reactions associated with irinotecan (CPT-11)-based chemotherapy. The correlation between UGT1A1 polymorphisms and the clinical efficacy of CPT-11 was also analyzed, along with the influence of age and tumor type.

Patients and methods: Patients administered a CPT-11-based regimen in the Beijing Cancer Hospital from April 2015 to September 2016 were included in our study ( $n=81)$. Blood samples for detecting UGT1A1 were collected from each patient after various administration regimens.

Results: Colorectal cancer patients with the $U G T 1 A 1 * 6$ mutant genotype had a significantly higher risk of severe delayed diarrhea than that of wild-type individuals when administered a CPT-11 dose $\geq 130 \mathrm{mg} / \mathrm{m}^{2}(P=0.042)$; the same phenomenon was observed when the UGT1Al *6 and $U G T 1 A 1 * 28$ mutant genotypes were considered together $(P=0.028)$. However, in lung cancer patients administered a low dose of CPT $-11, U G T 1 A 1 * 6 / * 28$ variants were not significantly associated with severe neutropenia or delayed diarrhea. Furthermore, adult patients with the $U G T 1 A 1 * 6$ mutation were more likely to develop severe delayed diarrhea than did wild-type adults ( $P=0.013$ ); however, the difference was not significant in elderly patients. No significant differences in tumor response were found among the different genotypes $(P>0.05)$.

Conclusion: Thus, age and tumor type influence our ability to predict adverse reactions based on UGT1A1 gene polymorphisms in cancer patients. Further, UGT1A1 gene polymorphisms are not correlated with the efficacy of CPT-11-based regimens.

Keywords: CPT-11, uridine diphosphate glucuronosyltransferase 1A1, SN-38, digital fluorescence molecular hybridization

\section{Plain language summary}

Pharmacogenetic testing of uridine diphosphate glucuronosyltransferase $1 \mathrm{~A} 1$ (UGT1A1) *6/*28 is recommended in clinical practice prior to the administration of irinotecan (CPT-11)-based regimens; however, the research results are not uniform. We need to conduct more research and perform more rigorous experiments to verify the results. In this study, we analyzed the relationship between $U G T 1 A 1 * 6 / * 28$ gene polymorphisms and adverse reactions, as well as the clinical efficacy of CPT-11 and the influence of age and tumor type. We found that colorectal cancer patients with the $U G T 1 A 1 * 6$ mutant genotype had a significantly higher risk of severe delayed diarrhea than that of wild-type individuals when administered a CPT-11 dose $\geq 130 \mathrm{mg} / \mathrm{m}^{2}$ $(P=0.042)$. Further, the same phenomenon was observed when the $U G T 1 A 1 * 6$ and $U G T 1 A 1 * 28$ mutant genotypes were considered together $(P=0.028)$; however, no significant difference in lung cancer patients was observed (all $P>0.05$ ). Furthermore, adult patients with the $U G T 1 A I^{*} 6$ 
mutation were more likely to develop severe delayed diarrhea than did wild-type adults ( $P=0.013)$. No significant differences in tumor response were found among the different genotypes $(P>0.05)$. Moreover, UGT1A1 gene polymorphisms were not correlated with the efficacy of CPT-11-based regimens.

\section{Introduction}

Irinotecan (CPT-11), a semisynthetic camptothecin (CPT) derivative, was initially isolated from Camptotheca acuminata in the early 1960s. ${ }^{1}$ It exerts high antineoplastic activity via inhibition of topoisomerase I (topo I) and is widely used to treat solid tumors in lung, colorectal, gastric, esophageal, cervical, ovarian, and other types of cancers..$^{2-4}$ However, CPT-11 can cause many adverse reactions, including delayed diarrhea and neutropenia, which have limited its clinical application.

CPT-11 is hydrolyzed to 7-ethyl-10-hydroxy-camptothecin (SN-38) by carboxylesterases. SN-38 is an active form of CPT-11 and a thousand times more toxic than CPT-11.5-7 $\mathrm{SN}-38$ is converted into an inactive $\mathrm{SN}-38$ glucuronide (SN-38G) by uridine diphosphate-glucuronosyl transferases (UGTs) in the liver. Therefore, UGTs play a major role in SN-38 glucuronidation and may be related to CPT-11induced adverse reactions.

Recently, single nucleotide polymorphisms (SNPs) have been found to be essential genomic resources that can significantly influence responses to pharmacotherapy, and they can be used to predict whether a drug will produce adverse reactions. As UGTs play an important role in the metabolism of CPT-11, mutations in the UGT genes may decrease UGT activity, which subsequently affects the pharmacokinetics and toxicity of CPT-11. ${ }^{8,9}$

UGTs are divided into 2 families (UGT1 and UGT2), which in turn are further divided into 3 subfamilies (UGT1A, $U G T 2 A$, and $U G T 2 B) .{ }^{1,10}$ The UGT1A enzyme is present as 3 isozymes, namely, UGT1A1, UGT1A7, and UGT1A9. ${ }^{11}$ $U G T 1 A 1 * 6$ and $U G T 1 A 1 * 28$ are considered to be the most important alleles for preventing severe SN-38-induced adverse reactions such as neutropenia and delayed diarrhea. Asians with mutant genotypes are more likely to develop neutropenia and delayed diarrhea; however, Caucasians with mutant genotypes are more likely to develop neutropenia. ${ }^{12}$ Further, the prevalence of the UGT1A $1 * 6$ polymorphism is higher in Asian populations than that in Caucasian populations. Therefore, we considered the UGT1A1*6 polymorphism in Asian populations. Previously, studies have shown that UGT1A $1 * 6 / * 28$ gene polymorphisms can be used to assess the risk of neutropenia; Chinese people are more likely to suffer delayed diarrhea than Japanese and Thai people. ${ }^{12-16}$
In this study, we used digital fluorescence molecular hybridization (DFMH) to determine the UGT1A1 genotypes of cancer patients treated with CPT-11 in our hospital. We determined the relationship between $U G T 1 A 1^{*} 6$ and $U G T 1 A 1 * 28$ gene polymorphisms and the clinical efficacy and toxicity of CPT-11. In addition, we categorized the patients according to age and tumor type to examine the influence of these factors on the efficacy and toxicity of CPT- 11 .

\section{Patients and methods Patients}

All 81 patients administered a CPT-11-based regimen in the Beijing Cancer Hospital from April 2015 to September 2016 were recruited. For inclusion in our study, patients were required to have at least 2 cycles of CPT-11based chemotherapy. The study was reviewed and approved by the research and medical ethics committee of Beijing Cancer Hospital. Written informed consent was obtained from each patient after a brief description of the purpose and protocols of the study.

\section{Patient treatments}

\section{Lung cancer}

The following treatments were used for lung cancer patients: 1 ) irinotecan mono-therapy, which included intravenous infusion of $60 \mathrm{mg} / \mathrm{m}^{2}$ CPT- 11 on days 1,8 , and 15 (repeated every 4 weeks); 2) irinotecan plus cisplatin (IP) regimen, which included intravenous infusion of $60 \mathrm{mg} / \mathrm{m}^{2} \mathrm{CPT}-11$ on days 1,8 , and 15 and $60 \mathrm{mg} / \mathrm{m}^{2}$ cisplatin on days 1 and 2 (repeated every 4 weeks); and 3) IP regimen plus bevacizumab, which included the same dosage regimen as IP and $5 \mathrm{mg} / \mathrm{kg}$ bevacizumab on day 1 (repeated every 3 weeks) (Table 1).

\section{Colorectal cancer}

The following treatments were used for colorectal cancer patients: 1) FOLFIRI regimen, which included intravenous infusion of $180 \mathrm{mg} / \mathrm{m}^{2} \mathrm{CPT}-11,300 \mathrm{mg}$ folinic acid, and $400 \mathrm{mg} / \mathrm{m}^{2} 5$-fluorouracil (FU) on day 1 , then continuous infusion of $2,500 \mathrm{mg} / \mathrm{m}^{2} 5$-FU by infusion pump for $46 \mathrm{~h}$ (repeated every 2 weeks); 2) FOLFIRI regimen plus bevacizumab/cetuximab, which included the same dosage regimen as FOLFIRI, plus intravenous infusion of $250 \mathrm{mg} / \mathrm{m}^{2}$ cetuximab on day 1 , repeated each week, or $5 \mathrm{mg} / \mathrm{kg}$ bevacizumab on day 1, repeated every 2 weeks; 3) IP regimen, which included intravenous infusion of $130 \mathrm{mg} / \mathrm{m}^{2}$ CPT-11 on day 1 and $70 \mathrm{mg} / \mathrm{m}^{2}$ cisplatin on days 1 and 2 (repeated every 3 weeks); 4) CPT-11 plus bevacizumab, which 
Table I Treatment regimens

\begin{tabular}{|c|c|c|c|c|c|}
\hline Tumor & Regimen & $\begin{array}{l}\text { No. of patients } \\
(n=8 I)\end{array}$ & $\begin{array}{l}\text { Dose of CPT-II } \\
\left(\mathrm{mg} / \mathrm{m}^{2}\right)\end{array}$ & $\begin{array}{l}\text { Days on which CPT-I I } \\
\text { was administered }\end{array}$ & $\begin{array}{l}\text { Cycle } \\
\text { (weeks) }\end{array}$ \\
\hline \multirow[t]{3}{*}{ Lung cancer } & IP & 36 & 60 & $1,8,15$ & 4 \\
\hline & CPT-II monotherapy & 8 & 60 & $\mathrm{I}, 8,15$ & 4 \\
\hline & IP plus bevacizumab & 1 & 60 & $\mathrm{I}, 8,15$ & 3 \\
\hline \multirow[t]{5}{*}{ Colorectal cancer } & IP & 1 & 130 & 1 & 3 \\
\hline & FOLFIRI & 22 & 180 & 1 & 2 \\
\hline & FOLFIRI plus bevacizumab/cetuximab & 2 & 180 & I & 2 \\
\hline & CPT-II plus bevacizumab & 1 & 180 & I & 3 \\
\hline & CPT-II, capecitabine plus bevacizumab & 1 & 180 & 1 & 2 \\
\hline \multirow[t]{3}{*}{ Esophageal cancer } & IP & 2 & 130 & I & 3 \\
\hline & FOLFIRI & 1 & 180 & I & 2 \\
\hline & CPT-II plus apatinib mesylate & 6 & 150 & I & 2 \\
\hline
\end{tabular}

Abbreviations: CPT-II, irinotecan; IP, irinotecan plus cisplatin; FOLFIRI, folinic acid, 5-fluorouracil plus irinotecan.

included intravenous infusion of $180 \mathrm{mg} / \mathrm{m}^{2} \mathrm{CPT}-11$ on day 1 and $5 \mathrm{mg} / \mathrm{kg}$ bevacizumab on day 1 (repeated every 3 weeks); and 5) CPT-11, capecitabine plus bevacizumab, which included intravenous infusion of $180 \mathrm{mg} / \mathrm{m}^{2} \mathrm{CPT}-11$ on day $1,1,000 \mathrm{mg} / \mathrm{m}^{2}$ capecitabine on days $1-7$, and $5 \mathrm{mg} / \mathrm{kg}$ bevacizumab on day 1 (repeated every 2 weeks) (Table 1).

\section{Esophageal cancer}

The following treatments were used for esophageal cancer patients: 1) IP regimen, which included intravenous infusion of $130 \mathrm{mg} / \mathrm{m}^{2} \mathrm{CPT}-11$ on day 1 and $60 \mathrm{mg} / \mathrm{m}^{2}$ cisplatin on days 2 and 3 (repeated every 3 weeks); 2) CPT-11 plus apatinib mesylate, which included intravenous infusion of $150 \mathrm{mg} / \mathrm{m}^{2} \mathrm{CPT}-11$ on day 1 and $250 \mathrm{mg}$ apatinib mesylate once daily (repeated every 2 weeks); and 3) FOLFIRI regimen, which included the same dosage regimen as previously mentioned (Table 1).

\section{Evaluation criteria for drug toxicity}

Toxicity was evaluated based on the National Cancer Institute Common Toxicity Criteria for Adverse Events (NCI-CTCAE) Version 3.0. Adverse reactions attributable to CPT-11 include neutropenia, leukopenia, delayed diarrhea, nausea, and vomiting. These reactions were divided into 4 stages in accordance with the NCI-CTCAE, with stages III and IV representing severe reactions.

\section{Evaluation criteria for tumor response}

The Response Evaluation Criteria in Solid Tumors (RECIST) is a standardized set of criteria for measuring tumor responses. Tumor response was assessed by computed tomography (CT) after every 2 cycles of treatment. The cases were defined as a complete response (CR), partial response (PR), or progressive disease (PD).

\section{UGTIAI gene detection}

Blood samples were collected from each patient and placed in blood collection tubes containing ethylenediaminetetraacetic acid (EDTA) to prevent coagulation. The blood samples were then transferred to an Eppendorf (EP) tube and lysed using ammonium chloride (Sino-Era Jiyin Tech Co., Ltd., Beijing, China) for $5 \mathrm{~min}$. The samples were then centrifuged at $700 \times g$ for $5 \mathrm{~min}$ to obtain plasma samples. Leukocyte genomic DNA was extracted directly from the blood samples using a nucleic acid purification kit (Sino-Era Jiyin Tech Co., Ltd.) and vortexed for $1 \mathrm{~min}$. After $15 \mathrm{~min}$ of stasis, universal sequencing kits (Sino-Era Jiyin Tech Co., Ltd.) for individual gene loci were used to determine the UGT1A1 genotype. $U G T 1 A 1 * 6$ and $U G A T 1 A 1 * 28$ gene polymorphisms were then identified by DFMH using fluorescent probes (Tianlong Science and Technology Co., Ltd., Xi'an, China).

DFMH is a new technique that is based on the principle of fluorescence in situ hybridization (FISH). Specific DNA strains containing fluorophore-labeled nucleotides can be used as probes to identify complementary sequences.

The conditions for sequencing by fluorescence molecular hybridization were as follows: 1) for the UGT1A1* 6 system, initial pre-degeneration at $95^{\circ} \mathrm{C}$ was performed for $10 \mathrm{~min}$, followed by 50 cycles of degeneration at $95^{\circ} \mathrm{C}$ for $30 \mathrm{~s}$ and revival at $62^{\circ} \mathrm{C}$ for $75 \mathrm{~s}$ and 2) for the $U G T 1 A 1 * 28$ system, initial pre-degeneration at $95^{\circ} \mathrm{C}$ was performed for $10 \mathrm{~min}$, followed by 50 cycles of degeneration at $95^{\circ} \mathrm{C}$ for $30 \mathrm{~s}$ and revival at $64^{\circ} \mathrm{C}$ for $75 \mathrm{~s}$.

\section{UGTIAI genotype analysis}

UGT1A1*6(G/G, G/A, and A/A) and UGT1A1*28 (TA6/6, $\mathrm{TA} 6 / 7$, and TA7/7) genotypes were used as quality control samples (Sino-Era Jiyin Tech Co., Ltd.) to set the range of parameters, which were determined by measuring the time 
to reach the specific fluorescent signal intensity (ST). ST1 and ST2 values reflect the interaction between the 2 probes and template and the different times to reach the specific fluorescent intensity, respectively; therefore, we set the parameter range by calculating the difference using the following formula:

$$
\Delta \mathrm{ST}=\mathrm{ST} 1-\mathrm{ST} 2
$$

Depending on the $\Delta \mathrm{ST}$ value, a threshold for the fluorescent signal can be set to facilitate genotype determination. The $\Delta \mathrm{ST}$ value ranges for the $U G T 1 A 1 * 6 / * 28$ genotypes were calculated using quality control samples. The specific genotype corresponds to a specific range of $\Delta \mathrm{ST}$. Therefore, we determined the genotype of each patient using the $\Delta \mathrm{ST}$ value ranges of the $U G T 1 A 1 * 6$ and $U G T 1 A 1 * 28$ genotypes. Results of $U G T 1 A 1 * 6 / * 28$ quality control gene polymorphism tests are shown in Figure 1A-F.

\section{Statistics}

Data were analyzed using SPSS Version 22.0 software (IBM Corporation, Armonk, NY, USA). Genotyping data were analyzed for deviation from the Hardy-Weinberg equilibrium using the chi-square test. Differences in the incidence of adverse reactions and the clinical efficacy of CPT-11 were also analyzed using the chi-square test and Fisher's exact test. All statistical analyses were 2-sided tests, and a $P$-value $\leq 0.05$ was defined as statistically significant.

\section{Results}

\section{Distribution of UGTIAI gene polymorphisms}

Complete genotyping was performed for all 81 patients, of whom 67 were men $(82.72 \%)$ and 14 were women $(17.28 \%)$. Thirty three patients $(40.74 \%)$ were $\geq 60$ years old, and 48 patients $(59.26 \%$ ) were $<60$ years old; the median patient age was 58 years (range: 28-79 years). The clinical characteristics of the patients are shown in Table 2, and results of the $U G T 1 A 1 * 6$ and $U G T 1 A 1 * 28$ genotyping are shown in Figure $2 \mathrm{~A}-\mathrm{F}$. The $U G T 1 A 1 * 28$ genotype was divided into 3 groups: wild-type (TA6/6), heterozygous mutant (TA6/7), and homozygous mutant (TA7/7), with 61 (75.31\%), $16(19.75 \%)$, and $4(4.49 \%)$ of the cases, respectively. The UGT1A1*6 genotype was similarly divided into wild-type $(\mathrm{G} / \mathrm{G})$, heterozygous mutant (G/A), and homozygous mutant (A/A) groups, with 62 (76.54\%), 17 (20.99\%), and 2 (2.47\%) of the cases, respectively. In total, there were 9 possible genotype combinations when both $U G T 1 A 1 * 6$ and $U G T 1 A 1 * 28$ were taken into consideration. These genotypes were divided into 3 categories depending on the number of mutations: double wild-type ( $\mathrm{G} / \mathrm{G}$ and TA6/6, $\mathrm{n}=44,54.32 \%$ ), single-site mutation (G/G and TA6/7 or G/A and TA6/6, $n=29,35.80 \%$ ), and 2-site mutations (G/G and TA7/7, G/A and TA6/7, or $\mathrm{A} / \mathrm{A}$ and TA6/6, $\mathrm{n}=8,9.88 \%$ ). However, we were unable to find the remaining 3 combinations (G/A and TA7/7, A/A and TA6/7, and A/A and TA7/7) in this study. The distribution of UGT1A1 gene polymorphisms is shown in Table 3. The genotype distributions of $U G T 1 A 1 * 6 / * 28$ were in accordance with the Hardy-Weinberg equilibrium $(P>0.05)$.

\section{Correlation between UGTIAI genotype and adverse reactions}

The different adverse reactions attributable to CPT- 11 in patients, such as leukopenia, neutropenia, delayed diarrhea, and nausea and vomiting, were recorded in this study. In total, 32 patients (39.51\%) suffered from leukopenia, 28 (34.57\%) from neutropenia, 39 (48.15\%) from nausea and vomiting, and $26(32.10 \%)$ from delayed diarrhea. The results show that mutant $U G T 1 A 1 * 6$ and $U G T 1 A 1 * 28$ genotypes, as well as mutant $U G T 1 A 1 * 6 / * 28$ genotypes considered together, increase the risk of severe diarrhea over that of wild-type individuals; however, the differences were not significant ( $P=0.305, P=0.707$, and $P=0.354$, respectively). In addition, there were no significant differences in the incidence of severe leukopenia, neutropenia, or nausea and vomiting in patients with UGT1A1 gene polymorphisms (Table 4).

\section{Correlation between UGTIAI genotype and adverse reactions with different tumors}

The patients were divided into 2 groups according to tumor type. One group included 45 lung cancer patients treated with a low dose of CPT-11 $\left(<130 \mathrm{mg} / \mathrm{m}^{2}\right)$, and the other group comprised 27 colorectal cancer patients treated with a high dose of CPT-11 ( $\left.\geq 130 \mathrm{mg} / \mathrm{m}^{2}\right)$. The relationship between UGTIA1 genotype and adverse reactions with different cancers is shown in Table 5. In lung cancer patients, the risk of grade I/II nausea and vomiting was higher in those with the $U G T 1 A 1 * 6$ mutant genotypes $(40.00 \% ; 4 / 10)$ than those with the wild-type UGT1A1 (17.14\%; 6/35). UGT1A1*28 mutant genotypes $(18.18 \% ; 2 / 11)$ resulted in a higher risk of grade I/II neutropenia than the wild-type genotype (5.88; 2/34); however, the difference was not statistically significant $(P=0.247)$. Thus, neither the wild-type nor mutant genotypes were significantly associated with severe adverse reactions in lung cancer patients. However, the outcome was 
A
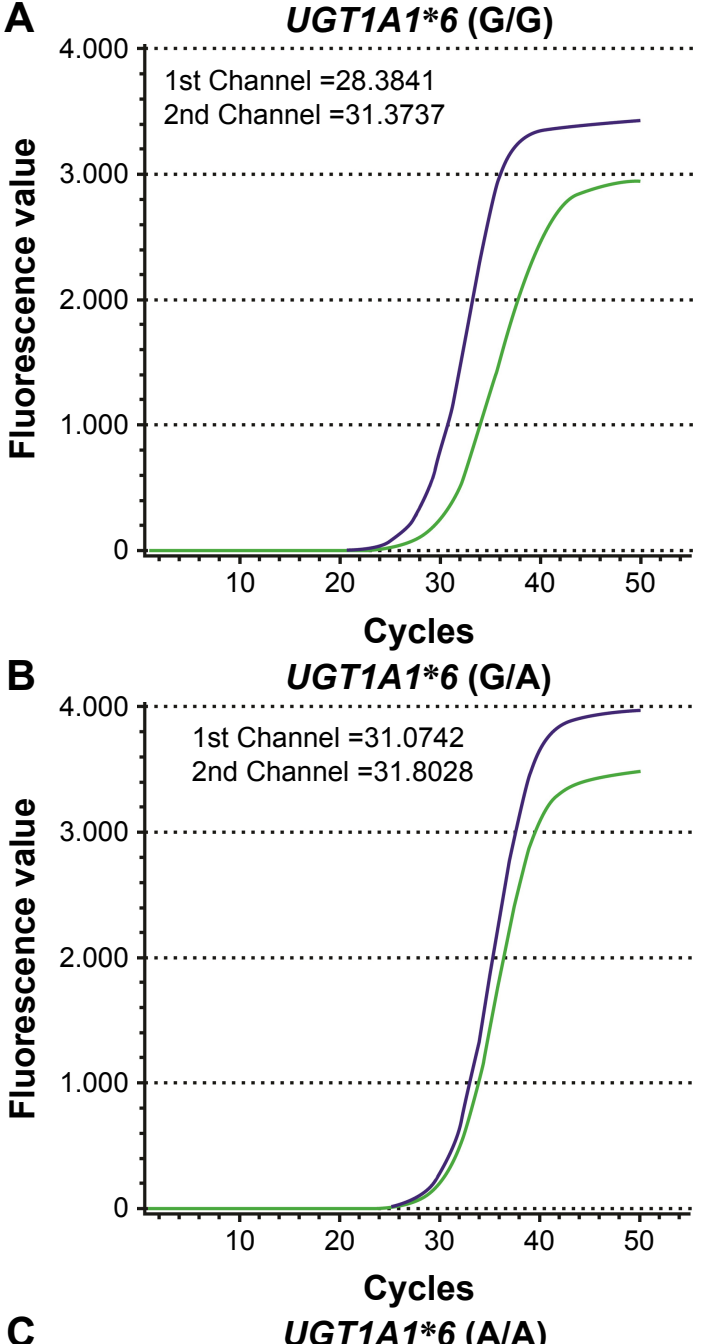

C

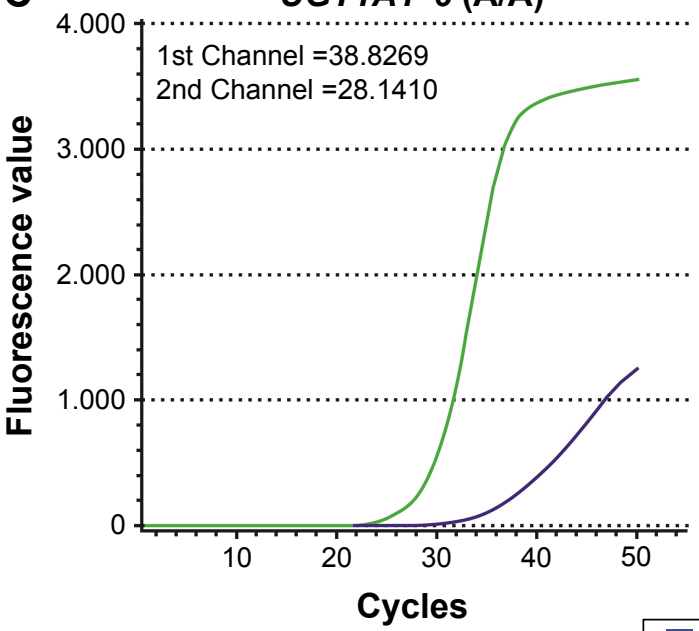

D UGT1A1*28 (TA6/6)

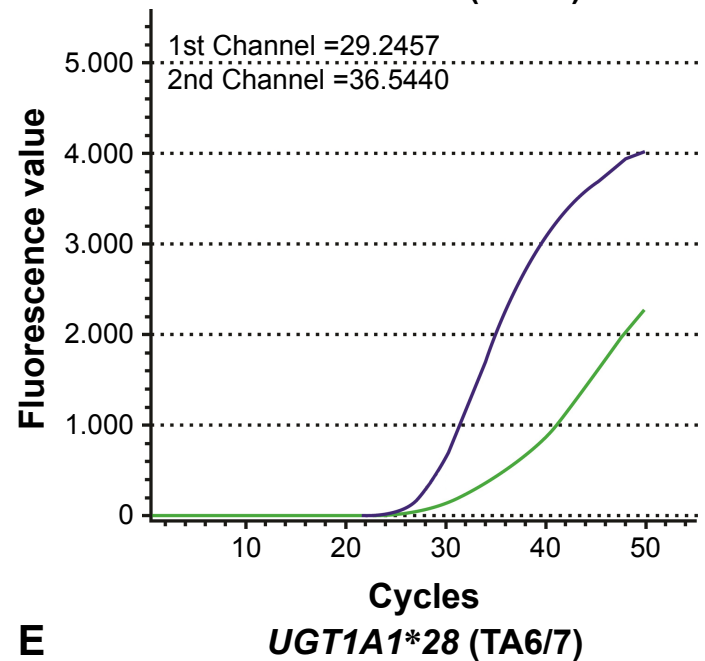

E UGT1A1*28(TA6/7)

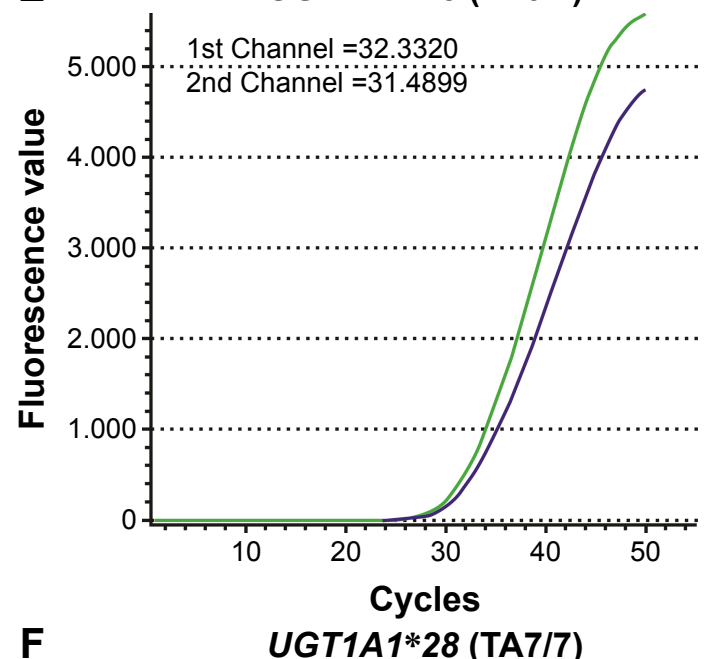

$\mathbf{F}$

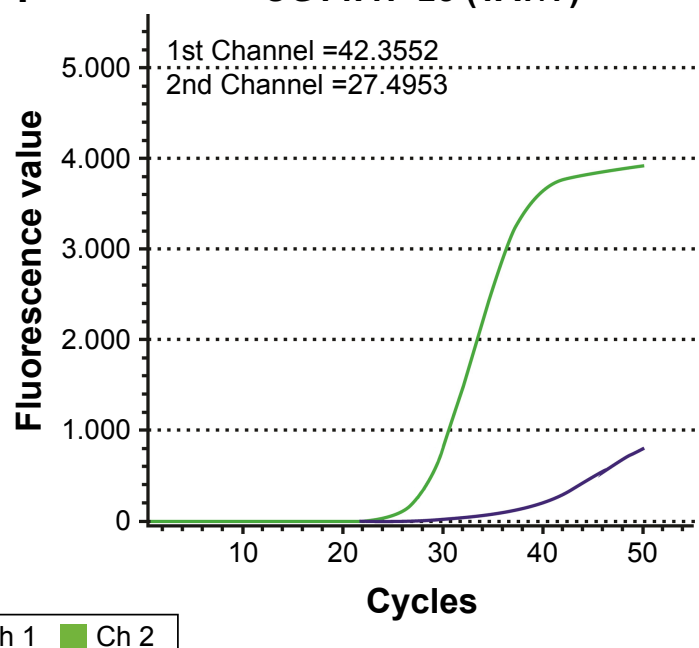

Figure I Detection of gene polymorphisms in UGTIAI*6 and UGTIAI*28 quality control genes by DFMH.

Notes: UGTIAI gene polymorphisms were detected using different fluorescent probes specific for UGTIAI*6 or UGTIAI*28 wild-type or mutant genotypes. The time to reach the specific fluorescence ST was determined for each channel using the fluorescence detector software, Microseq (Tianlong Science and Technology Co., Ltd., Xi'an, China). $\triangle S T$ was calculated to set the range of $\triangle S T$ values indicative of each UGTIAI polymorphism, which could then be used to determine the genotype of each patient. The results were as follows: (A) UGTIAI*6 (G/G), $\Delta S T=-2.9896 ;(B)$ UGTIAI*6 (G/A), $\Delta S T=-0.7286 ;($ C) UGTIAI*6 (A/A), $\Delta S T=\mid 0.6859 ;($ D) UGTIAI*28 (TA6/6), $\Delta S T=-7.2983$; (E) UGTIAI*28 (TA6/7), $\Delta S T=0.8421$; and (F) UGTIAI*28 (TA7/7), $\Delta S T=\mid 4.8599$. The maximum value of $\Delta S T$ is 5 . Therefore, the $\Delta S T$ values of UGTIAI*6 (G/A), UGTIAI*6 (G/G), and UGTIAI*6 (A/A) were between -2.0657 and $5.000,<-2.0657$, and $>5.000$, respectively, and the $\Delta S T$ values of UGTIAI*28 (TA6/7), UGTIAI*28 (TA6/6), and UGTIAI*6 (TA7/7) were between -3.5868 and $5.000,<-3.5868$, and $>5.000$, respectively.

Abbreviations: DFMH, digital fluorescence molecular hybridization; ST, signal intensity. 
Table 2 Clinical characteristics of patients with irinotecan-based treatment in this study

\begin{tabular}{|c|c|c|}
\hline Characteristics & $\begin{array}{l}\text { No. of patients } \\
(n=8 I)\end{array}$ & Frequency (\%) \\
\hline Mean age, years (range) & $58(28-79)$ & \\
\hline \multicolumn{3}{|l|}{ Gender } \\
\hline Male & 67 & 82.72 \\
\hline Female & 14 & 17.28 \\
\hline \multicolumn{3}{|l|}{ ECOG performance status } \\
\hline 0 & 47 & 58.02 \\
\hline 1 & 31 & 38.27 \\
\hline 2 & 2 & 2.47 \\
\hline 3 & 1 & 1.23 \\
\hline \multicolumn{3}{|l|}{ Type of tumor } \\
\hline Lung cancer & 45 & 55.56 \\
\hline Colorectal cancer & 27 & 33.33 \\
\hline Esophageal cancer & 9 & II.II \\
\hline \multicolumn{3}{|c|}{ Habit of smoking and drinking } \\
\hline Smoking & 20 & 24.69 \\
\hline Drinking & 5 & 6.17 \\
\hline Smoking and drinking & 31 & 38.27 \\
\hline None & 25 & 34.57 \\
\hline \multicolumn{3}{|l|}{ Line of treatment } \\
\hline First line & 30 & 37.04 \\
\hline Second line & 47 & 58.02 \\
\hline Third line & 4 & 4.94 \\
\hline \multicolumn{3}{|l|}{ Cycle of treatment } \\
\hline Second cycle & 34 & 41.98 \\
\hline Third cycle & 24 & 29.63 \\
\hline$\geq$ fourth cycle & 23 & 28.40 \\
\hline
\end{tabular}

Abbreviation: ECOG, Eastern Cooperative Oncology Group.

different in the colorectal cancer group. The risk of severe delayed diarrhea was significantly higher in patients with the UGT1A1*6 mutant genotypes $(42.86 \% ; 3 / 7)$ than those with the wild-type genotype $(5.00 \% ; 1 / 20)(P=0.042)$. Similarly, severe delayed diarrhea was higher in patients with the mutant UGT1A1 *28 genotypes $(28.57 \% ; 2 / 7)$ than those with the wild-type genotype $(10.00 \% ; 2 / 20)$; however, the difference was not significant $(P=0.269)$. When the $U G T 1 A 1 * 6$ and $U G T 1 A 1 * 28$ mutant genotypes were considered together, the incidence of severe delayed diarrhea was significantly higher than that of the wild-type genotype $(P=0.028)$.

\section{Correlation of UGTIAI genotype and adverse reactions in aging patients}

The patients were divided into 2 groups depending on their age. One group included 33 elderly patients $(\geq 60$ years old), and the other comprised 48 adult patients ( $<60$ years old). The relationship between age and adverse reactions associated with different UGTIAI genotypes is shown in Table 6. In adult patients, the incidence of severe delayed diarrhea was higher in patients with the $U G T 1 A 1 * 6$ mutant genotypes than those with the wild-type genotype ( $P=0.013)$, while the $U G T 1 A 1 * 28$ genotype had no significant effect on delayed diarrhea. When the UGT1A1*6 and UGT1A1*28 mutant genotypes were considered together $(12.50 \% ; 3 / 24)$, the risk of delayed diarrhea was higher than that of the wildtype genotype $(0 \% ; 0 / 24)$; however, the difference was not statistically significant $(P=0.233)$. In elderly patients, the incidence of grade I/II nausea and vomiting was higher in patients with the UGTIA1*6 mutant genotypes than those with the wild-type genotype $(P=0.039)$. Patients with $U G T 1 A 1 * 28$ polymorphisms were more likely to suffer from grade I/II neutropenia; however, the difference was not significant $(P=0.093)$. The incidence of severe delayed diarrhea in elderly patients carrying a UGT1A1*28 mutation $(16.67 \% ; 1 / 6)$ was higher than in those with wild-type UGT1A1 (7.41\%;2/27; P=0.464). No significant differences in adverse reactions associated with CPT-11 in elderly patients were observed when UGT1A1*6 and UGT1A1*28 were considered together.

\section{Correlation of UGTIAI genotype and tumor response}

Tumor response was assessed in $30(66.67 \% ; 30 / 45)$ patients with lung cancer and $19(70.37 \%$; 19/27) patients with colorectal cancer, respectively (Table 7). PR, stable disease (SD), and PD were observed in 6, 17, and 7 lung cancer cases and 4, 12, and 3 colorectal cancer cases, respectively. Colorectal patients with $U G T 1 A 1 * 28$ mutant genotypes had a good tumor response in the PR group; however, the difference was not significant $(P=0.178)$.

\section{Discussion}

CPT-11 causes obvious adverse reactions, including myelosuppression and delayed diarrhea, which limit its clinical application. The rapid growth of pharmacogenetics has shown that differences in drug metabolism between individuals are associated with genetic polymorphisms. Pharmacogenetic research has shown that genetic disparities play a major role in pharmacokinetics and can explain the clinical profile of many drugs, especially antineoplastic agents. ${ }^{17-19}$ For example, UGT1A1 plays an important role in $\mathrm{SN}-38$ metabolism. The different $U G T 1 A 1 * 6 / * 28$ genotypes result in different metabolic rates, and elevated SN-38 blood concentrations induce adverse reactions. Therefore, it may be possible to predict the likelihood of $\mathrm{SN}-38$-induced adverse reactions in patients using $U G T 1 A 1 * 6 / * 28$ genotyping. 
A
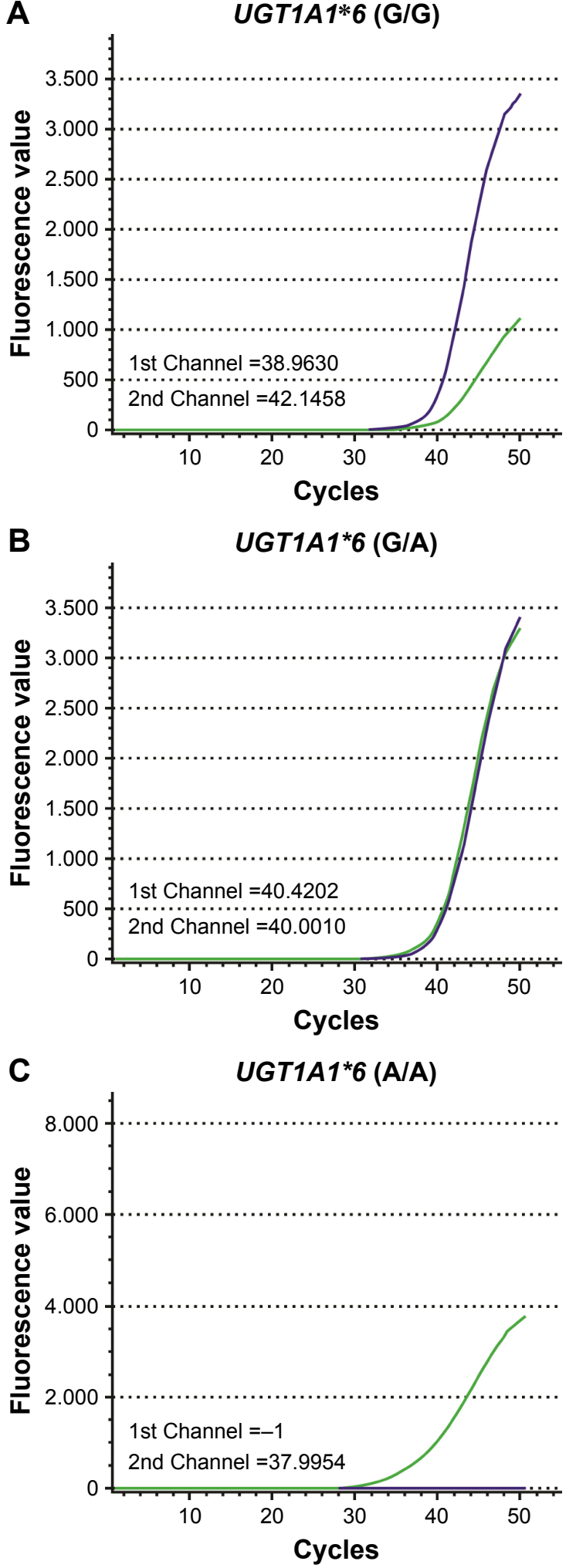
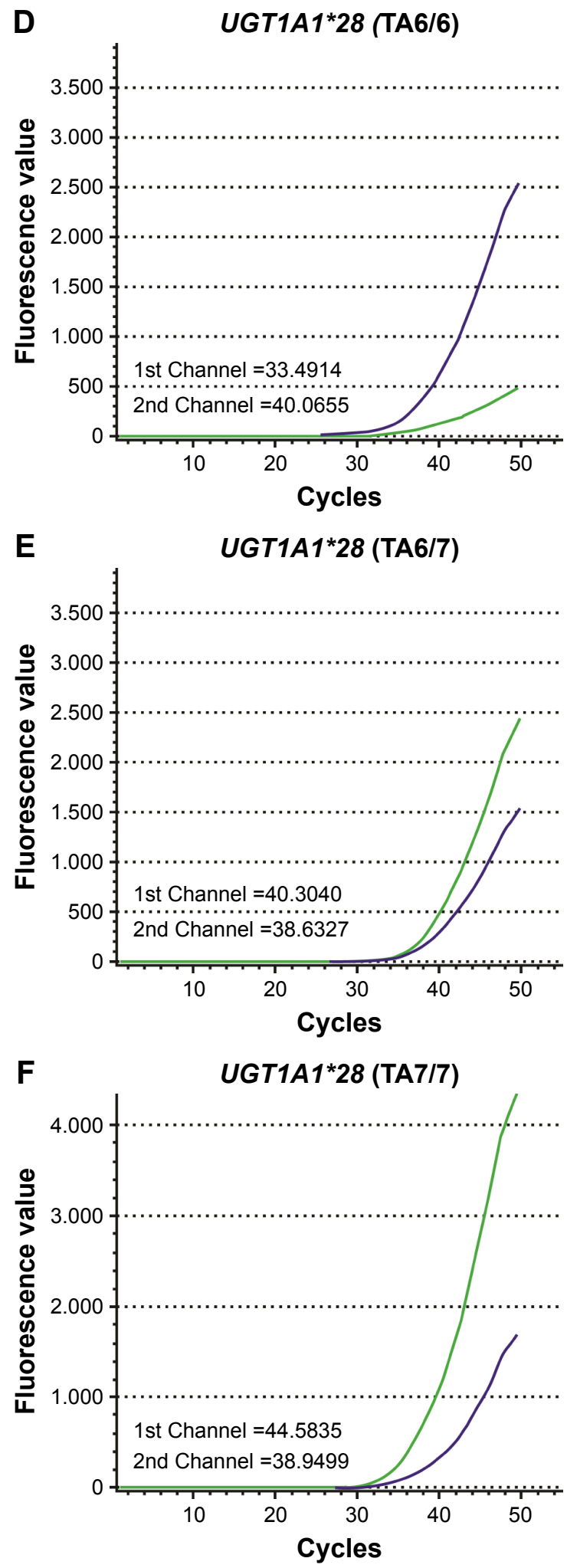

Ch 1 Ch 2

Figure 2 UGTIAI gene polymorphisms in patients.

Notes: Blood samples from the patients were analyzed by DFMH, and the results are as follows: $(\mathbf{A}) \Delta \mathrm{ST}=-3.1828$, representing UGTIAI*6 (G/G); (B) $\Delta S T=0.4 I 92$, representing UGTIAI*6 (G/A); (C) $\Delta S T=12.0046$, representing UGTIAI*6 (A/A); (D) $\Delta S T=-6.574 I$, representing UGTIAI*28 (TA6/6); (E) $\Delta S T=I .67 I 3$, representing UGTIAI*28 (TA6/7); and (F) $\Delta S T=5.6336$, representing UGTIAI*28 (TA7/7).

Abbreviations: DFMH, digital fluorescence molecular hybridization; ST, signal intensity. 
Table 3 Distribution of UGTIAI gene polymorphisms

\begin{tabular}{lll}
\hline Genotype & $\begin{array}{l}\text { No. of patients } \\
(\mathbf{n}=\mathbf{8} \text { I) }\end{array}$ & Ratio (\%) \\
\hline UGTIAI*6 & & \\
G/G & 62 & 76.54 \\
G/A & 17 & 20.99 \\
A/A & 2 & 2.47 \\
UGTIAI*28 & & \\
TA6/6 & $6 I$ & 75.31 \\
TA6/7 & 16 & 19.75 \\
TA7/7 & 4 & 4.94 \\
UGTIAI combinations & & \\
G/G TA6/6 & 44 & 54.32 \\
G/G TA6/7 & 14 & 17.28 \\
G/A TA6/6 & 15 & 18.52 \\
G/G TA7/7 & 4 & 4.94 \\
G/A TA6/7 & 2 & 2.47 \\
A/A TA6/6 & 2 & 2.47 \\
\hline
\end{tabular}

Recently, the association between UGTIA1 gene polymorphisms and adverse reactions, particularly delayed diarrhea and neutropenia, has been of interest worldwide. Many studies have shown that UGT1A1*28 is significantly associated with CPT-11-induced toxicity, especially neutropenia. ${ }^{20-24}$ Caucasians with mutant genotypes are more likely to have neutropenia. ${ }^{12}$ However, UGT1A1 * 6 is more prevalent in Asian countries than in Caucasian populations, suggesting that $U G T 1 A 1 * 6$ polymorphisms should be considered in addition to $U G T 1 A 1 * 28$ polymorphisms for more individualized CPT-11-based chemotherapy. In Japan, Hoskins et $\mathrm{a}^{25}$ discovered that the risk of severe hematologic toxicity is higher in patients with $U G T 1 A 1 * 28$ homozygous mutations than in patients with wild-type or heterozygous genotypes at a dose $>150 \mathrm{mg} / \mathrm{m}^{2}$, but not $<125 \mathrm{mg} / \mathrm{m}^{2}$. However, Hirasawa et $\mathrm{al}^{26}$ found that UGT1A1*6/*28 mutations are associated with an increased risk of neutropenia and delayed diarrhea at a low dose of CPT- 11 . In China, Xu et $\mathrm{al}^{3}$ discovered that mutant $U G T 1 A 1 * 6 / * 28$ genotypes significantly increase the incidence of delayed diarrhea, and the incidence of neutropenia is significantly increased when the $U G T 1 A 1 * 6$ and $U G T 1 A 1 * 28$ genotypes are considered together. Further, Chinese patients with UGT1A1*6/*28 mutations are more likely to suffer delayed diarrhea than Japanese patients. Our results demonstrate that the UGTIA1 * 6 mutant genotypes are associated with delayed diarrhea in colorectal cancer patients $(P=0.042)$. In addition, when both $U G T 1 A 1 * 6$ and $U G T 1 A 1 * 28$ genotypes are taken into consideration, we discovered that the risk of severe delayed diarrhea is significantly higher in colorectal patients with mutant genotypes $(P=0.028)$. However, in our study, there was no association between UGT1A1 mutations and severe hematologic toxicity. Besides, we did not find DPYD mutations (rs55886062, rs67376798, or rs3918290) in our study; therefore, we could eliminate the effects of fluorouracil drug metabolism on adverse reactions.

The occurrence of cancer is increasing because of population growth and aging. ${ }^{27}$ Hence, more attention should be paid to elderly patients, and individualized medication programs should be implemented to reduce the incidence of adverse reactions. In our study, UGTIA1*6 mutations (G/A and A/A) increased the risk of grade I/II nausea and vomiting specifically in elderly patients $(P=0.039)$. In contrast, adult patients with $U G T 1 A 1 * 6$ mutations had a significantly higher risk of severe delayed diarrhea $(P=0.013)$; however, there were no significant differences in elderly patients. Differences in drug metabolism may not be obvious in elderly patients owing to reduced body function and metabolic enzyme activity.

Table 4 Relationship between UGTIAI*6/*28 genotype and the incidence of adverse reactions associated with CPT-I I

\begin{tabular}{|c|c|c|c|c|c|c|c|c|}
\hline \multirow[t]{2}{*}{ Genotyping } & \multicolumn{2}{|c|}{ Leukopenia, n (\%) } & \multicolumn{2}{|c|}{ Neutropenia, n (\%) } & \multicolumn{2}{|c|}{ Nausea and vomiting, $\mathrm{n}(\%)$} & \multicolumn{2}{|c|}{ Diarrhea, n (\%) } \\
\hline & Grades I-II & Grades III-IV & Grades I-II & Grades III-IV & Grades I-II & Grades III-IV & Grades I-II & Grades III-IV \\
\hline $\mathrm{G} / \mathrm{G}(\mathrm{n}=62)$ & $19(30.65)$ & 7 (I I.29) & $14(22.58)$ & II (I7.74) & $26(4 I .94)$ & $4(6.45)$ & I7 (27.4I) & $3(4.84)$ \\
\hline $\mathrm{G} / \mathrm{A}(\mathrm{n}=17)$ & $5(29.4 I)$ & I (5.88) & $0(0)$ & $3(17.65)$ & $8(47.06)$ & $0(0)$ & $3(17.65)$ & $3(17.65)$ \\
\hline $\mathrm{A} / \mathrm{A}(\mathrm{n}=2)$ & $0(0)$ & $0(0)$ & $0(0)$ & $0(0)$ & I (50.00) & $0(0)$ & $0(0)$ & $0(0)$ \\
\hline$P$-value & 1.000 & 1.000 & 0.067 & 1.000 & 0.908 & 0.614 & 0.739 & 0.305 \\
\hline TA6/6 $(n=6 I)$ & $18(29.5 \mathrm{I})$ & 7 (I I.48) & $10(16.39)$ & II (18.03) & $27(44.26)$ & $3(4.92)$ & $15(24.59)$ & $4(6.56)$ \\
\hline TA6/7 $(n=16)$ & $5(31.25)$ & I (6.25) & $3(18.75)$ & $2(12.50)$ & $7(43.75)$ & I (6.35) & $4(25.00)$ & $2(12.50)$ \\
\hline TA7/7 $(n=4)$ & I $(25.00)$ & $0(0)$ & I (25.00) & I (25.00) & I (25.00) & $0(0)$ & I (25.00) & $0(0)$ \\
\hline$P$-value & 1.000 & 1.000 & 0.757 & 0.646 & 0.844 & 1.000 & 1.000 & 0.707 \\
\hline Wild-type $(n=44)$ & $13(29.55)$ & $6(13.64)$ & $10(22.73)$ & $8(18.18)$ & $19(43.18)$ & $3(6.38)$ & $12(27.27)$ & $2(4.55)$ \\
\hline $\begin{array}{l}\text { Single-site mutant } \\
(\mathrm{n}=29)\end{array}$ & $10(34.48)$ & $2(9.60)$ & $3(10.34)$ & $5(17.24)$ & $13(44.83)$ & I (3.45) & $7(24.13)$ & $3(10.34)$ \\
\hline $\begin{array}{l}\text { Two-site mutant } \\
(\mathrm{n}=8)\end{array}$ & I (I2.50) & $0(0)$ & I (I2.50) & I (I2.50) & $3(37.50)$ & $0(0)$ & I (I2.50) & I (12.50) \\
\hline$P$-value & 0.483 & 0.357 & 0.365 & 0.926 & 1.000 & 1.000 & 0.670 & 0.354 \\
\hline
\end{tabular}


Table 5 Relationship between UGTIAI*6/*28 genotype and the incidence of adverse reactions associated with different tumors

\begin{tabular}{|c|c|c|c|c|c|c|c|c|c|}
\hline \multirow[t]{2}{*}{ Tumor } & \multirow[t]{2}{*}{ Genotyping } & \multicolumn{2}{|c|}{ Leukopenia, n (\%) } & \multicolumn{2}{|c|}{ Neutropenia, n (\%) } & \multicolumn{2}{|c|}{$\begin{array}{l}\text { Nausea and vomiting, } \\
\text { n (\%) }\end{array}$} & \multicolumn{2}{|c|}{ Diarrhea, n (\%) } \\
\hline & & Grades I-II & Grades III-IV & Grades I-II & Grades III-IV & Grades I-II & Grades III-IV & Grades I-II & Grades III-IV \\
\hline Lung & $\mathrm{G} / \mathrm{G}(\mathrm{n}=35)$ & $7(20.00)$ & $6(17.14)$ & $4(11.43)$ & $4(11.43)$ & $6(17.14)$ & $4(11.43)$ & $10(28.57)$ & $2(5.7 I)$ \\
\hline cancer & $\begin{array}{l}\mathrm{G} / \mathrm{A} A / \mathrm{A} \\
(\mathrm{n}=10)\end{array}$ & $3(30.00)$ & $0(0)$ & $0(0)$ & $0(0)$ & $4(40.00)$ & $0(0)$ & $2(20.00)$ & $0(0)$ \\
\hline$P$-value & & 0.811 & 0.379 & $0.56 \mathrm{I}$ & $0.56 \mathrm{I}$ & 0.270 & 0.561 & 0.893 & 1.000 \\
\hline Colorectal & $\mathrm{G} / \mathrm{G}(\mathrm{n}=20)$ & $7(35.00)$ & I (5.00) & $5(25.00)$ & $6(30.00)$ & $15(75.00)$ & $0(0)$ & $5(25.00)$ & I (5.00) \\
\hline cancer & $\begin{array}{l}\mathrm{G} / \mathrm{A} A / \mathrm{A} \\
(\mathrm{n}=7)\end{array}$ & I (I4.29) & $0(0)$ & $0(0)$ & I (14.29) & $4(57.14)$ & $0(0)$ & I (14.29) & $3(42.86)$ \\
\hline$P$-value & & 0.633 & 1.000 & 0.283 & 0.633 & 0.633 & NG & 1.000 & 0.042 \\
\hline Lung & TA6/6 $(n=34)$ & 7 (20.59) & $5(|4.7|)$ & $2(5.88)$ & $3(8.82)$ & $8(23.53)$ & $3(8.82)$ & $8(23.53)$ & $2(5.88)$ \\
\hline cancer & $\begin{array}{l}\text { TA6/7 TA7/7 } \\
(\mathrm{n}=\mathrm{II})\end{array}$ & $3(27.27)$ & I (9.09) & $2(18.18)$ & I (9.09) & $2(18.18)$ & I (9.09) & $4(36.36)$ & $0(0)$ \\
\hline$P$-value & & 0.963 & 1.000 & 0.247 & 1.000 & 1.000 & 1.000 & 0.657 & 1.000 \\
\hline Colorectal & TA6/6 $(n=20)$ & $6(30.00)$ & I $(5.00)$ & $4(20.00)$ & $5(25.00)$ & $14(70.00)$ & $0(0)$ & $5(25.00)$ & $2(10.00)$ \\
\hline cancer & $\begin{array}{l}\text { TA6/7 TA7/7 } \\
(\mathrm{n}=7)\end{array}$ & $2(28.57)$ & $0(0)$ & I (14.28) & $2(28.57)$ & $5(71.43)$ & $0(0)$ & I (14.29) & $2(28.57)$ \\
\hline$P$-value & & 1.000 & 1.000 & 1.000 & 1.000 & 1.000 & NG & 1.000 & 0.269 \\
\hline $\begin{array}{l}\text { Lung } \\
\text { cancer }\end{array}$ & $\begin{array}{l}\text { Wild-type } \\
(n=24)\end{array}$ & $4(16.67)$ & $5(20.83)$ & $2(8.33)$ & $3(12.50)$ & $3(12.50)$ & $3(12.50)$ & $6(25.00)$ & $2(8.33)$ \\
\hline & $\begin{array}{l}\text { Mutant type } \\
(\mathrm{n}=2 \mathrm{I})\end{array}$ & $6(28.57)$ & I (4.76) & $2(9.52)$ & I (4.76) & $6(28.57)$ & I (4.76) & $6(28.57)$ & $0(0)$ \\
\hline$P$-value & & 0.549 & 0.253 & 1.000 & 0.700 & 0.331 & 0.700 & 1.000 & 0.491 \\
\hline $\begin{array}{l}\text { Colorectal } \\
\text { cancer }\end{array}$ & $\begin{array}{l}\text { Wild-type } \\
(n=15)\end{array}$ & $5(33.33)$ & I (6.67) & $4(26.67)$ & $4(26.67)$ & II (73.33) & $0(0)$ & $4(26.67)$ & $0(0)$ \\
\hline & $\begin{array}{l}\text { Mutant type } \\
(n=12)\end{array}$ & $3(25.00)$ & $0(0)$ & I (8.33) & $3(25.00)$ & $8(66.67)$ & $0(0)$ & $2(16.67)$ & $4(33.33)$ \\
\hline$P$-value & & 0.696 & 1.000 & 0.342 & 1.000 & 1.000 & NG & 0.662 & 0.028 \\
\hline
\end{tabular}

Abbreviation: NG, not given.

Table 6 Relationship between UGTIAI genotype and the incidence of adverse reactions in patients of different ages

\begin{tabular}{|c|c|c|c|c|c|c|c|c|c|}
\hline \multirow[t]{2}{*}{ Age } & \multirow[t]{2}{*}{ Genotyping } & \multicolumn{2}{|c|}{ Leukopenia, n (\%) } & \multicolumn{2}{|c|}{ Neutropenia, n (\%) } & \multicolumn{2}{|c|}{ Nausea and vomiting, n (\%) } & \multicolumn{2}{|c|}{ Diarrhea, n (\%) } \\
\hline & & Grades I-II & Grades III-IV & Grades I-II & Grades III-IV & Grades I-II & Grades III-IV & Grades I-II & Grades III-IV \\
\hline \multirow[t]{2}{*}{$<60$} & $\mathrm{G} / \mathrm{G}(\mathrm{n}=36)$ & $13(36.11)$ & $5(13.89)$ & $6(16.67)$ & $7(19.44)$ & $16(44.44)$ & $0(0)$ & $10(27.78)$ & $0(0)$ \\
\hline & $\begin{array}{l}\text { G/A A/A } \\
(n=12)\end{array}$ & $3(27.27)$ & I (9.09) & $0(0)$ & $2(18.18)$ & $3(27.27)$ & $0(0)$ & $0(0)$ & $3(25.00)$ \\
\hline$P$-value & & 0.724 & 1.000 & 0.313 & 1.000 & 0.394 & NG & 0.101 & 0.013 \\
\hline \multirow[t]{2}{*}{$\geq 60$} & G/G $(n=26)$ & $6(23.08)$ & $2(7.69)$ & 8 (30.77) & $4(15.38)$ & $10(38.46)$ & $4(15.38)$ & 7 (26.92) & 3 (I I.54) \\
\hline & $\begin{array}{l}\text { G/A A/A } \\
(n=7)\end{array}$ & $2(33.33)$ & $0(0)$ & $0(0)$ & I (I6.67) & $6(85.7 \mathrm{I})$ & $0(0)$ & I (I4.28) & $0(0)$ \\
\hline$P$-value & & 1.000 & 1.000 & 0.154 & 1.000 & 0.039 & 0.555 & 0.652 & 1.000 \\
\hline \multirow[t]{2}{*}{$<60$} & TA6/6 $(n=34)$ & II (32.35) & $5(|4.7|)$ & $6(17.65)$ & $6(17.65)$ & II (32.35) & $0(0)$ & 7 (20.59) & $2(5.88)$ \\
\hline & $\begin{array}{l}\text { TA6/7 TA7/7 } \\
(n=\mid 4)\end{array}$ & $3(27.27)$ & I (9.09) & I (9.09) & $3(21.43)$ & $6(42.86)$ & $0(0)$ & $4(28.57)$ & I (7.|4) \\
\hline$P$-value & & 0.684 & 0.810 & 0.626 & 1.000 & 0.719 & NG & 0.826 & 1.000 \\
\hline \multirow[t]{2}{*}{$\geq 60$} & TA6/6 $(n=27)$ & 7 (25.93) & $2(7.4 I)$ & $4(\mid 4.8 I)$ & $5(18.52)$ & 16 (59.26) & $3(\mathrm{II} . \mathrm{II})$ & $8(29.63)$ & $2(7.4 I)$ \\
\hline & $\begin{array}{l}\text { TA6/7 TA7/7 } \\
(n=6)\end{array}$ & $3(50.00)$ & $0(0)$ & $3(50.00)$ & $0(0)$ & $2(40.00)$ & I $(20.00)$ & I (I6.67) & I (I6.67) \\
\hline$P$-value & & 0.336 & 1.000 & 0.093 & 0.556 & 0.375 & 1.000 & 1.000 & 0.464 \\
\hline \multirow[t]{2}{*}{$<60$} & $\begin{array}{l}\text { Wild-type } \\
(n=24)\end{array}$ & 7 (29.17) & $4(16.67)$ & $5(20.83)$ & $4(16.67)$ & $9(37.50)$ & $0(0)$ & $6(25.00)$ & $0(0)$ \\
\hline & $\begin{array}{l}\text { Mutant type } \\
(n=24)\end{array}$ & $6(33.33)$ & $2(I I . I I)$ & I (5.56) & $5(20.83)$ & $9(37.50)$ & $0(0)$ & $5(20.83)$ & $3(12.50)$ \\
\hline$P$-value & & 0.754 & 0.663 & 0.190 & 1.000 & 1.000 & NG & 1.000 & 0.233 \\
\hline \multirow[t]{2}{*}{$\geq 60$} & $\begin{array}{l}\text { Wild-type } \\
(n=20)\end{array}$ & $6(30.00)$ & $2(10.00)$ & $5(25.00)$ & $4(20.00)$ & I0 (50.00) & $3(15.00)$ & $7(35.00)$ & $2(10.00)$ \\
\hline & $\begin{array}{l}\text { Mutant type } \\
(n=13)\end{array}$ & $5(38.46)$ & $0(0)$ & $3(23.08)$ & I (9.09) & $7(53.85)$ & I (9.09) & $3(23.07)$ & I (7.69) \\
\hline$P$-value & & $0.7 \mid 4$ & 0.508 & 1.000 & 0.625 & 1.000 & 1.000 & 0.701 & 1.000 \\
\hline
\end{tabular}

Abbreviation: NG, not given. 
Table 7 Relationship between UGTIAI genotypes and tumor response

\begin{tabular}{|c|c|c|c|c|c|c|c|}
\hline Tumor & Genotyping & PR, n (\%) & $P$-value & SD, n (\%) & $P$-value & PD, n (\%) & $P$-value \\
\hline \multirow[t]{6}{*}{ Lung cancer } & $G / G(n=2 I)$ & $3(14.28)$ & 0.320 & $13(61.90)$ & 0.443 & $5(23.8 I)$ & 1.000 \\
\hline & G/A A/A $(n=9)$ & $3(33.33)$ & & $4(44.44)$ & & $2(22.22)$ & \\
\hline & TA6/6 $(n=23)$ & $5(21.74)$ & 1.000 & $13(56.52)$ & 1.000 & $5(21.74)$ & 1.000 \\
\hline & TA6/7 TA7/7 $(n=7)$ & I (14.29) & & $4(57.14)$ & & $2(28.57)$ & \\
\hline & Wild-type $(n=14)$ & $2(14.29)$ & 0.657 & $9(64.29)$ & 0.484 & $3(21.43)$ & 1.000 \\
\hline & Mutant type $(n=16)$ & $4(25.00)$ & & $8(50.00)$ & & $4(25.00)$ & \\
\hline \multirow[t]{6}{*}{ Colorectal cancer } & $G / G(n=14)$ & $4(28.57)$ & 0.530 & $8(57.14)$ & 0.603 & $2(14.28)$ & 1.000 \\
\hline & $\mathrm{G} / \mathrm{A} A / \mathrm{A}(\mathrm{n}=5)$ & $0(0)$ & & $4(80.00)$ & & I (20.00) & \\
\hline & TA6/6 $(n=15)$ & $2(13.33)$ & 0.178 & $10(66.67)$ & 0.603 & $3(20.00)$ & 1.000 \\
\hline & TA6/7 TA7/7 $(n=4)$ & $2(50.00)$ & & $2(50.00)$ & & $0(0)$ & \\
\hline & Wild-type $(n=I I)$ & $2(18.18)$ & 1.000 & $7(63.64)$ & 1.000 & $2(18.18)$ & 1.000 \\
\hline & Mutant type $(\mathrm{n}=8)$ & $2(25.00)$ & & $5(62.50)$ & & I (I2.50) & \\
\hline
\end{tabular}

Abbreviations: PR, partial response; SD, stable disease; PD, progressive disease.

There are currently no uniform conclusions regarding the correlation between UGT1A1 gene polymorphisms and the clinical efficacy of CPT-11. Some studies have demonstrated that CPT-11 is more efficacious in patients with mutant genotypes. ${ }^{28,29}$ However, most studies have found no correlation between different UGT1A1 genotypes and clinical efficacy ${ }^{30,31}$ Further, a meta-analysis of 6,087 patients found that both homozygous and heterozygous $U G T 1 A 1 * 28$ mutant types had a higher response than wild-type patients, particularly Caucasians. ${ }^{12}$ In our study, we observed that the tumor response in patients with $U G T 1 A 1 * 28$ mutant genotypes with colorectal cancer was better than in those with the wildtype genotype; however, the difference was not statistically significant $(P=0.178)$.

A limitation of this study is its retrospective design; therefore, we did not conduct patient follow-ups once they discontinued treatment in our hospital. Consequently, we did not conduct a survival analysis in addition to the tumor response analysis to evaluate efficacy. Further, the small sample size of this study may impact the results. Owing to the low $U G T 1 A 1 * 6$ and $U G T 1 A 1 * 28$ mutation rates, we need to increase sample size and perform more rigorous experiments to verify the results of this study.

\section{Conclusion}

UGTIA1 is a potential pharmacogenetic marker for detecting the occurrence of severe delayed diarrhea, especially in colorectal cancer patients receiving a high dose of CPT-11. However, neither $U G T 1 A 1 * 6$ nor $U G T 1 A 1 * 28$ mutations were associated with severe neutropenia. UGT1A1 gene polymorphisms cannot predict the clinical outcome of CPT-11-based regimens.

\section{Acknowledgment}

We would like to thank Editage (www.editage.com) for English language editing and publication support.

\section{Disclosure}

The authors report no conflicts of interest in this work.

\section{References}

1. Mathijssen R, van Alphen RJ, Verweij J, et al. Clinical pharmacokinetics and metabolism of irinotecan (CPT-11). Clin Cancer Res. 2001; 7(8):2182-2194.

2. Xiao XG, Xia S, Zou M, et al. The relationship between UGTIAl gene polymorphism and irinotecan effect on extensive-stage small-cell lung cancer. Onco Targets Ther. 2015;8:3575-3583.

3. Xu C, Tang X, Qu Y, Keyoumu S, Zhou N, Tang Y. UGT1A1 gene polymorphism is associated with toxicity and clinical efficacy of irinotecan-based chemotherapy in patients with advanced colorectal cancer. Cancer Chemother Pharmacol. 2016;78(1):119-130.

4. Kim M, Keam B, Kim TM, et al. Phase II study of irinotecan and cisplatin combination chemotherapy in metastatic, unresectable esophageal cancer. Cancer Res Treat. 2016;49(2):416-422.

5. Lopes F, Smith R, Nash S, Mitchell RT, Spears N. Irinotecan metabolite SN38 results in germ cell loss in the testis but not in the ovary of prepubertal mice. Mol Hum Reprod. 2016;22(11):745-755. Epub 2016 Jul 28 .

6. Fujita K, Sparreboom A. Pharmacogenetics of irinotecan disposition and toxicity: a review. Curr Clin Pharmacol. 2010;5(3):209-217.

7. Kawato Y, Aonuma M, Hirota Y, Kuga H, Sato K. Intracellular roles of SN-38, a metabolite of the camptothecin derivative CPT-11, in the antitumor effect of CPT-11. Cancer Res. 1991;51(16):4187-4191.

8. Miyata Y, Touyama T, Kusumi T, et al. UDP-glucuronosyltransferase $1 \mathrm{~A} 1 * 6$ and $* 28$ polymorphisms as indicators of initial dose level of irinotecan to reduce risk of neutropenia in patients receiving FOLFIRI for colorectal cancer. Int J Clin Oncol. 2016;21(4):696-703.

9. Yeh YS, Tsai HL, Huang CW, et al. Prospective analysis of UGTIA1 promoter polymorphism for irinotecan dose escalation in metastatic colorectal cancer patients treated with bevacizumab plus FOLFIRI as the first-line setting: study protocol for a randomized controlled trial. Trials. 2016;17:46.

10. Shimoyama S. Pharmacogenetics of irinotecan: an ethnicity-based prediction of irinotecan adverse events. World J Gastrointest Surg. 2010; 2(1):14-21. 
11. Inoue K, Sonobe M, Kawamura Y, et al. Polymorphisms of the UDPglucuronosyl transferase $1 \mathrm{~A}$ genes are associated with adverse events in cancer patients receiving irinotecan-based chemotherapy. Tohoku $J$ Exp Med. 2013;229(2):107-114.

12. Liu XH, Lu J, Duan W, et al. Predictive value of UGT1A1*28 polymorphism in irinotecan-based chemotherapy. J Cancer. 2017;8(4): 691-703.

13. Li M, Wang Z, Guo J, et al. Clinical significance of UGT1A1 gene polymorphisms on irinotecan-based regimens as the treatment in metastatic colorectal cancer. Onco Targets Ther. 2014;23(7): 1653-1661.

14. Gao J, Zhou J, Li Y, Lu M, Jia R, Shen L. UGT1A1 6/28 polymorphisms could predict irinotecan-induced severe neutropenia not diarrhea in Chinese colorectal cancer patients. Med Oncol. 2013;30(3):604.

15. Takano M, Yamamoto K, Tabata T, et al. Impact of UGT1A1 genotype upon toxicities of combination with low-dose irinotecan plus platinum. Asia Pac J Clin Oncol. 2016;12(2):115-124.

16. Atasilp C, Chansriwong P, Sirachainan E, et al. Correlation of UGT1A1(*)28 and (*)6 polymorphisms with irinotecan-induced neutropenia in Thai colorectal cancer patients. Drug Metab Pharmacokinet. 2016;31(1):90-94.

17. Deeken JF, Figg WD, Bates SE, Sparreboom A. Toward individualized treatment: prediction of anticancer drug disposition and toxicity with pharmacogenetics. Anticancer Drugs. 2007;18(2):111-126.

18. Lee W, Lockhart AC, Kim RB, Rothenberg ML. Cancer pharmacogenomics: powerful tools in cancer chemotherapy and drug development. Oncologist. 2005;10(2):104-111.

19. Deeken JF, Slack R, Marshall JL. Irinotecan and uridine diphosphate glucuronosyltransferase $1 \mathrm{~A} 1$ pharmacogenetics: to test or not to test, that is the question. Cancer. 2008;113(7):1502-1510.

20. Strassburg CP, Kalthoff S, Ehmer U. Variability and function of family 1 uridine-5'-diphosphate glucuronosyltransferases (UGT1A). Crit Rev Clin Lab Sci. 2008;45(6):485-530.

21. Shulman K, Cohen I, Barnett-Griness O, et al. Clinical implications of $U G T 1 A 1 * 28$ genotype testing in colorectal cancer patients. Cancer. 2011;117(14):3156-3162.
22. Gagne JF, Montminy V, Belanger P, Journault K, Gaucher G, Guillemette C. Common human UGT1A polymorphisms and the altered metabolism of irinotecan active metabolite 7-ethyl-10-hydroxycamptothecin (SN-38). Mol Pharmacol. 2002;62(3):608-617.

23. Wang Y, Shen L, Xu N, et al. UGT1A1 predicts outcome in colorectal cancer treated with irinotecan and fluorouracil. World J Gastroenterol. 2012;18(45):6635-6644.

24. Kim TW, Innocenti F. Insights, challenges, and future directions in irinogenetics. Ther Drug Monit. 2007;29(3):265-270.

25. Hoskins JM, Goldberg RM, Qu P, Ibrahim JG, McLeod HL. $U G T 1 A 1 * 28$ genotype and irinotecan-induced neutropenia: dose matters. J Natl Cancer Inst. 2007;99(17):1290-1295.

26. Hirasawa A, Zama T, Akahane T, et al. Polymorphisms in the UGT1A1 gene predict adverse effects of irinotecan in the treatment of gynecologic cancer in Japanese patients. J Hum Genet. 2013;58(12):794-798.

27. Torre LA, Bray F, Siegel RL, Ferlay J, Lortet-Tieulent J, Jemal A. Global cancer statistics, 2012. CA Cancer J Clin. 2015;65(2):87-108.

28. Douillard JY, Cunningham D, Roth AD, et al. Irinotecan combined with fluorouracil compared with fluorouracil alone as first-line treatment for metastatic colorectal cancer: a multicentre randomised trial. Lancet. 2000;355(9212):1041-1047.

29. Saltz LB, Cox JV, Blanke C, et al. Irinotecan plus fluorouracil and leucovorin for metastatic colorectal cancer. Irinotecan Study Group. N Engl J Med. 2000;343(13):905-914.

30. McLeod HL, Sargent DJ, Marsh S, et al. Pharmacogenetic predictors of adverse events and response to chemotherapy in metastatic colorectal cancer: results from North American Gastrointestinal Intergroup Trial N9741. J Clin Oncol. 2010;28(20):3227-3233.

31. Glimelius B, Garmo H, Berglund A, et al. Prediction of irinotecan and 5-fluorouracil toxicity and response in patients with advanced colorectal cancer. Pharmacogenomics J. 2011;11(1):61-71.
OncoTargets and Therapy

\section{Publish your work in this journal}

OncoTargets and Therapy is an international, peer-reviewed, open access journal focusing on the pathological basis of all cancers, potential targets for therapy and treatment protocols employed to improve the management of cancer patients. The journal also focuses on the impact of management programs and new therapeutic agents and protocols on

\section{Dovepress}

patient perspectives such as quality of life, adherence and satisfaction. The manuscript management system is completely online and includes a very quick and fair peer-review system, which is all easy to use. Visit http://www.dovepress.com/testimonials.php to read real quotes from published authors. 